International Review of Research in Open and Distributed Learning Volume 16, Number 4

October - 2015

\title{
Editorial - Volume 16, Issue Number 4
}

\author{
Dr. Dianne Conrad \\ Co-Editor, IRRODL
}

Have I mused before in this spot on the vagaries of assembling each journal issue? Yes, I know I have, because each opportunity to engage one more time with a diverse collection of new works reminds me of a gift-receiving occasion: What will I open first? What will it be? Which part of my life will it enrich? In this case, however, the gift is yours, and our job as editors is just to package it up in the most attractive way possible.

Themes always strike me as a good organizing tool, perhaps a hold-over from dissertation-writing days. Our themes within the pages of IRRODL have been changing and expanding. You noted the special OER and MOOC issue recently released, edited by my co-editor, Rory McGreal, and our corresponding journal "refresh" to focus more directly on OER and the notion of "open" in education. This issue features three articles dealing with "open," and two more that address issues of social media.

That said, this issue opens on more traditional turf with four articles that highlight learning through the lens of learners' experiences. The first, by Brown, Hughes, Keppell, Hard and Smith, with the literarily-intriguing title "Twenty shades of grey: Stories from students in their first semester of distance learning," seeks a deeper understanding from first-time distance learners of the nature of their experiences. Framed around design-based research and involving a mixed method approach over three phases, the study focuses on the third phase, concluding that learners' lives are not black-and-white; they are complex shades of grey and, as such, more consideration and support should come their way from designers and institutions.

The second article by Rashid, Jahan, Islam and Ratna examines a more specific issue, that of student enrolment and dropout at the Bangladesh Open University. Their study explores the factors that pull students to enroll in the program and then push them to dropout. The findings indicate an unsatisfactory level of dropout, concluding that improvement is needed in instructional strategy and the provision of timely course-related information and materials.

Chang follows with the "Alteration of Influencing Factors of Continued Intentions to Use eLearning for Different Degrees of Adult Online Participation," in which the alteration of influencing factors of continued intentions to use e-learning in different levels of participation was investigated. Data were collected and analyzed using the Structural Equation Modeling (SEM) and DeLone and McLean's Revised Information System Success Model as well as Rogers' 
Innovation Adoption Theory. The results revealed that the quality of the system contributed to the variance between low and high levels of participation.

In the fourth learner-experience centred article, Junas, Santoso, Isal and Utomo's "Useability Evaluation of the Student Centered e-Learning Environment," the authors report on usability testing conducted on the Student Centered e-Learning Environment (SCeLE), in which undergraduate learning activities, in a blended online learning mode, were targeted at Fasilkom University. Both qualitative and quantitative data were gathered. Their research produced eight recommendations including solutions to tackle the identified useability problems.

The next two articles focus on m-learning. Bhatti's article, "An Investigation of University Student Readiness towards M-learning using Technology Acceptance Model," used TAM because of its perceived robust and parsimonious nature. The study's final results, based on 244 valid responses, indicated that students' skills and psychological readiness strongly influenced their perceived ease of use and usefulness of m-learning, whereas both these constructs positively influenced their behavioral intention to use m-learning.

Liaw and Huang follow, also on the topic of m-learning, with their study on how factors of personal attitudes and learning environments affect gender difference as regards mobile learning acceptance. They contend that, although mobile devices facilitate accessing Internet resources anytime and anywhere, the relationship between gender perspectives and m-learning environments has been a controversial topic. From 159 questionnaire responses their statistical analyses showed that both female and male learners have highly positive perceptions toward $\mathrm{m}$ learning but that personal attitudes and learning environments outweigh gender differences in $\mathrm{m}$ learning acceptance.

Pitt offers the first of three articles that discuss aspects of OER with "Mainstreaming Open Textbooks: Educator Perspectives on the Impact of OpenStax College open textbooks." Note that the recent special edition on OER and MOOCs also contained a piece on OpenStax, and, without giving away any secrets, I can hint that another is under review at the moment. A hot topic? This paper presents the results of collaborative research between OpenStax College, which has published 16 open textbooks to date, and the OER Research Hub, a Hewlett-funded open research project examining the impact of open educational resources (OER) on learning and teaching. These surveys focused on use and perceptions of OER and OpenStax College materials, financial savings and perceptions of impact on both educators and students.

In "Supporting Access to Open Online Courses for Learners of Developing Countries," Nti examines, from a learner's perspective, how access to, and use of OER may be enhanced for nonnative learners in developing countries. Nti demonstrates that a three-level relationship includes the open concept, access, and participation in OER. This relationship is affected by technology, economic, and more importantly, social factors, all of which play dual and opposite roles. The open concept forms the foundation of the three-level relationship, while access 
maintains a central role from which participation, including use, repurposing, and redistribution of OER depend. Nti proposes that the relationship among openness, access, and participation should be a major consideration for producers and providers of OER content who seek to support access for nonnative learners, particularly those in developing countries.

Again on the topic of OER, Cohen, Reisman, and Sperling, in "Personal Spaces in Public Repositories as a Facilitator for Open Educational Resource Usage," explored the use of personal space use to gain insight into OER user behavior by analyzing those behaviours in the Bookmark Collection of MERLOT. Their study concluded that members created personal spaces for their own use, while allowing others to view and copy; or for other users. Personal space encourages the reuse of learning materials and enables the construction of unique learning processes that suit the learner's needs.

From OER to social media.. how big a leap is that? Product versus process? Parallel processes? Open and distributed learning - and this journal - is taking on accordion-like characteristics as ODL's educational turf evolves and expands. The first of two social media-focused articles in this issue comes from Malaysia. Al Rahmi, Othman, and Yusuf, in "The Role of Social Media for Collaborative Learning to Improve Academic Performance of Students and Researchers in Malaysian Higher Education," explore the factors contributing to the enhancement of collaborative learning and engagement through social media. Invoking constructivist theory, they found that collaborative learning, engagement and intention to use social media positively and significantly relate to the interactivity of students and researchers with their supervisors to improve their academic performance in Malaysian higher education.

In our last research article, also discussing social media, Norman, Nordin, Din, Ally, and Dogan provide a social network analysis to explore the roles of social participation in mobile social media learning, basing their study on the premise that the availability of mobile technology has made it an ubiquitous tool for social interaction. Data were collected from discussions among students using Facebook groups and analyzed using the social network analysis tool, NodeXL. Findings showed four roles of social participation in mobile social media: (i) lurkers; (ii) gradually mastering members/ passive members; (iii) recognized members; and (iv) coaches.

\section{But wait! There's more!}

IRRODL has long offered scholars and researchers the opportunity to bring forth "notes from the field" and/ or technical notes. These pieces are not full-on research studies although they may be preparatory to them or pieces of them. They may also be reflective pieces. In this issue, Rohr, Costello and Hawkins marry the Twitter-verse to education in "Design Considerations for Integrating Twitter into an Online Course," positing that although the use of Twitter for communication and assessment activities in online courses is not new, it faces challenges, especially in high enrolment courses. They describe a Twitter Evaluation application and describe how it improved the assessment process of grading Tweet events.

This work is licensed under a Creative Commons Attribution 4.0 International License. 
This issue also feature another installment of "Leadership Notes," which is introduced by Dr. Marti Cleveland-Innes in the Notes section.

(C) Conrad

\section{Athabasca University $\mathbf{n}$}

(c) 